\title{
Mars probe lost through 'management faults'
}

Washington. The project management and systems engineering procedures used by the US National Aeronautics and Space Administration (NASA) on its Mars Observer mission have been scathingly attacked by two panels responsible for investigating the failure of the mission.

A last-minute change to the flight plan of the spacecraft probably led to the mission's demise last September, when contact was lost as it entered its orbit around the planet and prepared to release equipment on to its surface (see Nature 365, 3; 1993).

But the post mortem on the mission's failure, made public in Washington last week, has pointed to more fundamental causes, cataloguing a pattern of loose management and non-existent systems engineering on the $\$ 980$-million project.

A report to NASA from an independent panel chaired by Timothy Coffey, research director at the Naval Research Laboratory in Washington, found the space agency's management of the programme failed to adapt as

\section{Will NASA make up for lost data?}

Washington. Scientists who lost instruments on the Mars Observer would like to see a re-flight of an identical spacecraft in 1996 to achieve the mission's scientific objectives. But according to officia!s at the US National Aeronautics and Space Administration (NASA), the agency is more likely to split the experiment payload between two or more smaller spacecraft - that is, if it can afford any new missions at all.

Ironically, the failure of the Mars Observer makes a re-flight the safest, and probably the cheapest, option for recovering global Mars data, according to Arden Albee, a project scientist at the California Institute of Technology.

Albee says that, because investigating committees from inside and outside NASA have gone over the spacecraft design in meticulous detail, the Mars observer is much better understood than any new spacecraft would be. In addition, he says, spares for most of the main instrument components have already been procured.

Launching a single 'Mars Observer 2' is unlikely, however, given the embarrassing and conspicuous failure of the first spacecraft. Dan Goldin, NASA's administrator, is said to be against the idea, partly because of the way it would be perceived outside the agency.

One principal investigator suggests that re-flying the same spacecraft, even if it makes technical sense, would be "politically incorrect". A Mars Observer 2 mission would also require either a Shuttle flight (which are all booked) or a Titan rocket (which is prohibitively expensive).

The preferred option at NASA headquarters is therefore to fly most or all of the seven original Mars Observer science instruments on smaller spacecraft that could be launched by cheaper Delta rockets. These would probably be sent to Mars during successive launch 'windows', which fall every two years.

The first possible opportunity would be in 1996. Goldin has already ruled out a make-up mission this year, as the only spacecraft that could have been ready in time would have been the Pentagon-developed Clementine (see Nature 363, 201; 1993), which would have yielded a minimal scientific return at Mars. "You would have been doing something just to do it," says Albee.

A team led by Charles Elachi, assistant director of NASA's Jet Propulsion Laboratory in Pasadena, California, spent last autumn looking at options to recover the data that were to have been collected by Mars Observer. This was designed to conduct a year-long global study of the planet's geology, surface chemistry and weather.

The team considered between 20 and 25 possibilities that could be ready for a 1996 launch. Most of them, however, involve adapting an Earth-orbiting spacecraft to fly to Mars, which presents another political problem, as that strategy was partly responsible for the Mars Observer failure (see story above).

Meanwhile, the scientists who lost experiments on Mars Observer are worried that if their instruments do not get selected for the first re-flight, the space agency will not have the funds for a second, and that even if it does, the original idea for the Mars Obsenver mission - a comprehensive, synoptic view of the planet - would be gone.

Indeed, many of the Mars Observer principal investigators, who lost a decade's work when the spacecraft disappeared in August, wonder if there will even be a 1996 launch. NASA already has a Mars mission on the books for that year - the MESUR (Mars Environmental Survey) Pathfinder, a small lander that will test technology for a future Mars surface network.

Advocates of the proposed Pluto Fast Flyby had also hoped for a new funding start in 1996 (see Nature 358, 701; 1992). With Congress and the White House warning that NASA can expect less money for space science next year than this year, the planetary community now has to contend with an unplanned mission elbowing its way into the funding queue.

Tony Reichhardt the concept of the Mars Observer changed radically, from the original idea of several craft based on existing technologies to the complex spacecraft that was finally launched by the agency in 1992 .

In effect, NASA developed a production-line system of standard missions based on cheap, readily available commercial satellite technology, and then used it to build a one-off interplanetary spacecraft, whose design was often heavily improvised. "The fundamental problem was they thought they had a routine mission, and they didn't," says John Pike, a space specialist with the Federation of American Scientists.

Coffey says that systematic weaknesses evolved in the programme as it developed over the years, and "the discipline and documentation culture was inappropriate for a one-of-a-kind mission". He adds that the fixed-price contract under which contractor Martin Marietta built the spacecraft was "appropriate for building things that you already know how to build".

The Coffey report finds that the most likely reason for the failure of the mission was the accidental mixing of a small quantity of fuel in the fuel-pressurization system, rupturing tubing and sending the craft into a slow spin.

If this did indeed happen, the spacecraft

\section{IMAGE UNAVAILABLE FOR COPYRIGHT REASONS}

Great expectations: the Mars Observer prior to its launch.

would have been unable to charge its batteries, and will now be "dead" and drifting through space, having failed to enter its planned orbit around Mars.

The panel found that the mixing of fuel is likely to have taken place because some fuel evaporated and leaked through check valves that were supposed to contain it on the 11-month mission to Mars. Tests conducted for the panel showed that two tablespoonfuls of fuel would have leaked in this 